
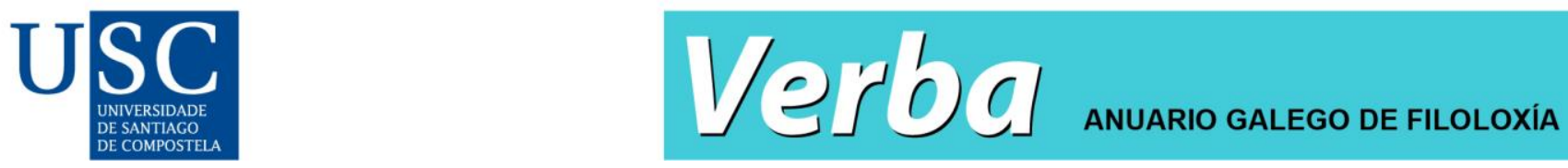

Verba: Anuario Galego de Filoloxía, 48, 2021. ISSN: 2174-4017

https://doi.org/10.15304/verba.48.6468

\title{
De las copulativas identificativas a las construcciones hendidas*
}

From identificational copulatives to cleft constructions

Manuel Pérez Saldanya ${ }^{1}$

1Universitat de València, España

Recibido: 17-12-2019; Aceptado: 10-02-2020

\section{Resumen}

En este trabajo se analizan los cambios estructurales que se han producido en las construcciones hendidas a lo largo de la historia del español. Se parte de la idea de que estas construcciones presentan inicialmente las características típicas de las oraciones copulativas y que progresivamente se alejan de las copulativas típicas por un proceso de gramaticalización creciente. La aparición del llamado que galicado se sitúa dentro de este proceso de gramaticalización, que también se asocia al aumento de frecuencia del orden de constituyentes más característico de las hendidas (i. e., las hendidas con cópula en posición inicial).

Palabras clave: construcciones hendidas, que galicado, foco estrecho, foco presentativo, gramaticalización.

\begin{abstract}
In this paper I analyze the main structural changes that cleft constructions have undergone in the history of Spanish. I start from the hypothesis that initially these constructions have the same features as typical copular clauses and that they gradually become more different from standard copula constructions through a process of grammaticalization. The appearance of the so-called Gallic que is a consequence of this grammaticalization process. Another consequence is that clefts with the copula in clause-initial position become more and more frequent.
\end{abstract}

Keywords: cleft constructions, que galicado, narrow focus, informative focus, grammaticalization. 


\section{INTRODUCCIÓN}

Las construcciones hendidas son un tipo especial de oraciones copulativas. Como es bien sabido, se trata de oraciones compuestas que contienen una cláusula principal con el verbo ser y una subordinada relativa (u oración equiparable), cuyo contenido proposicional puede expresarse mediante una oración simple paralela sin el verbo ser ni el relativo. La oración de (1a), por ejemplo, es una construcción hendida y presenta un contenido proposicional paralelo al de la oración (1b).

(1) a. Fue Guadalupe quien presentó ayer a la conferenciante.

b. Guadalupe presentó ayer a la conferenciante.

El objetivo de este trabajo es analizar los cambios sintácticos que se han producido en estas construcciones desde el castellano medieval al español contemporáneo y delimitar el proceso de gramaticalización que, de manera progresiva, aleja las construcciones hendidas de las copulativas más prototípicas y permite que adquieran un grado cada vez mayor de "identidad construccional". Con este objetivo, en el apartado 2 realizaremos una breve caracterización de las construcciones hendidas, y en los apartados 3, 4 y 5 analizaremos los cambios sintácticos que se han producido en este tipo de oraciones. Concretamente, distinguiremos tres tipos de construcciones: las más típicamente copulativas (apartado 3), las que pueden presentar un constituyente no nominal en la posición de sujeto (apartado 4) y las que contienen, además, el subordinante general que, conocido en la tradición gramatical hispánica como que galicado (apartado 5). Dedicamos el apartado 6 a un análisis más detallado de algunos aspectos controvertidos de este subordinante general, y el apartado 7 al cambio que se produce en el orden de los constituyentes en el español contemporáneo. En el apartado 8 se recogen las conclusiones y a continuación las obras del corpus utilizado y la bibliografía.

Para realizar el trabajo, partimos de un corpus que tiene en cuenta criterios diacrónicos, diatópicos y textuales. En el corpus se incluyen obras del siglo XIII al XXI. Para cada siglo se han analizado al menos cinco obras, que contienen un mínimo de 350000 palabras. Se ha tratado, además, de que las obras fueran representativas de diferentes géneros textuales, y a partir del siglo XVI se han tenido en cuenta obras tanto del español peninsular como del español americano, generalmente mexicanas, argentinas y uruguayas. Como corpus de control se han utilizado también los corpus informáticos de la Real Academia Española: el Corpus Diacrónico del Español (CORDE) y el Corpus de Referencia del Español actual (CREA), así como el corpus informático de la Academia Mexicana de la Lengua Corpus Diacrónico y Diatópico del Español de América (CORDIAM). Para el conjunto de obras analizadas, véase el corpus bibliográfico final en el apartado 9.

\section{CARACTERÍSTICAS GENERALES DE LAS CONSTRUCCIONES HENDIDAS}

En las construcciones hendidas del español, la subordinada relativa puede ser libre o semilibre. Es libre en el ejemplo recogido más arriba en (1a), que contiene un pronombre relativo, y también en los ejemplos de (2), que contienen un relativo adverbial. 
(2) a. Fue en México donde se celebró el congreso.

b. Fue ayer cuando nos conocimos.

c. Fue paseando como me di cuenta del error.

En estos ejemplos, el relativo posee propiedades léxicas que permiten que pueda utilizarse solo, sin ningún tipo de antecedente: es el caso del pronombre quien, que incorpora el rasgo 'humano', y de los relativos adverbiales, que pueden tener un significado locativo (donde), temporal (cuando) o modal (como). Son semilibres, en cambio, relativas como la de (3), en las que el relativo aparece precedido de un determinante definido, generalmente el artículo, que aporta las propiedades de género y número que corresponderían al antecedente.

(3) Fue Guadalupe la que presentó ayer a la conferenciante.

En las construcciones hendidas, el verbo copulativo permite escindir un constituyente oracional del resto de la predicación, que se expresa mediante la relativa ${ }^{1}$. Este constituyente hendido (o escindido) puede ser un argumento o un adjunto de predicado: es un argumento, y concretamente el argumento sujeto, en los ejemplos de (1a) y (3), y un adjunto de predicado en los ejemplos de (2).

Semánticamente, las hendidas son construcciones identificativas de carácter especificativo (De Cesare 2014: 9, Di Tullio 2010, Fernández Leborans 1999: 2398-2403, Moreno Cabrera 1999, Raga 2018: 134-141). Son construcciones identificativas porque establecen una identidad entre los dos constituyentes vinculados por la cópula, pero al mismo tiempo son especificativas, porque el constituyente hendido tiene un carácter referencial y especifica el elemento indeterminado expresado por el relativo. Dicho en otras palabras, en estas construcciones, la relativa es una proposición abierta, que contiene una variable, que se satura mediante el constituyente referencial hendido. Para un ejemplo como el de (1a), tendríamos, por lo tanto, una lectura equivalente a Una persona presentó ayer a la conferenciante y dicha persona es Guadalupe.

En los estudios sobre las hendidas es normal distinguir tres tipos de construcciones, teniendo en cuenta el orden de sus tres constituyentes: la cópula, el constituyente referencial (o hendido, escindido) y la relativa. Siguiendo la terminología inglesa, es habitual hablar de hendidas (4a), pseudohendidas (4b) y pseudohendidas inversas $(4 \mathrm{c})^{2}$.

(4) a. Hendida (Cópula-Constituyente Referencial-Relativa):

Fue Guadalupe quien presentó a la conferenciante.

b. Pseudohendida (Relativa-Cópula-Constituyente referencial):

Quien presentó a la conferenciante fue Guadalupe.

c. Pseudohendida inversa (Constituyente Referencial-Cópula-Relativa):

Guadalupe fue quien presentó a la conferenciante. 
Cuando sea necesario, en este trabajo nos referiremos a las diferentes construcciones indicando el constituyente que las encabeza. En todo caso, nos centraremos únicamente en las construcciones encabezadas por el constituyente referencial (Guadalupe fue...) o por la cópula (Fue Guadalupe...), y dejaremos de lado las encabezadas por la relativa (Quien presentó a la conferenciante fue... $)^{3}$.

Tanto las lenguas románicas como las anglogermánicas presentan construcciones hendidas y, por eso, algunos autores han considerado que se trata de una característica areal (Löfstedt 1966: 277, Metzeltin 1989), aunque en estudios más recientes se defiende la idea de que este tipo de construcciones reaparece, con variaciones, en lenguas tipológicamente muy diferentes (cf. Hartmann y Veenstra 2013: 3-9 y los artículos recogidos en el monográfico editado por estos autores).

Con independencia de que estas construcciones reaparezcan en lenguas diferentes, lo que resulta relevante desde una perspectiva comparativa e histórica es que no en todas las lenguas han alcanzado el mismo grado de gramaticalización. Centrándonos en las hendidas propiamente dichas (i. e., las encabezadas por la cópula), las del inglés o del francés se situarían en el extremo superior de la escala y las del rumano en el grado inferior, mientras que las del español ocuparían un grado intermedio ${ }^{4}$. Ejemplificaremos estas diferencias a partir de oraciones del inglés y de las paralelas del español. Como muestran los ejemplos de (5), las hendidas del inglés presentan un alto grado de gramaticalización y fijación sintáctica, dado que: (i) contienen un pronombre no referencial convencionalizado (it); (ii) este pronombre precede inmediatamente al verbo copulativo, que aparece fijado en tercera persona del singular del presente (is o la variante reducida 's), y (iii) la subordinada está encabezada por el subordinante general (that) o un relativo.

(5) a. It's Guadalupe that introduced the speaker yesterday.

'\{Es/Fue\} Guadalupe \{la que/quien\} presentó a la conferenciante ayer'

b. It's me that introduced the speaker yesterday.

'\{Soy/Fui\} yo \{el que/quien\} presentó al conferenciante ayer'

c. It's in Mexico that the congress was held.

'\{Es/Fue\} en México donde se celebró el congreso'

Como muestran las paráfrasis de estos ejemplos, las hendidas del español no presentan una estructura tan fijada. Por una parte, no contienen un pronombre no referencial y el verbo copulativo admite variación de persona, número y tiempo. Por otra, entre el constituyente referencial y el relativo se establece generalmente una concordancia funcional, de manera que si el primero es un sintagma preposicional o un adverbio como en la paráfrasis de (5c), el relativo ha de estar regido por una preposición o ha de ser un adverbio con una función semejante.

Si entre las lenguas románicas y anglogermánicas es posible establecer diferencias de gramaticalización, dentro de algunas lenguas también se constatan diferencias entre variedades geográficas. Por ejemplo, el grado de gramaticalización del portugués del Brasil es superior al del 
portugués europeo, y lo mismo ocurre si se compara el español americano y el peninsular. En el español peninsular, la oración inglesa de (4c) se construye mediante el relativo adverbial donde, mientras que en el español americano también es posible, y de hecho es la solución más habitual, el uso de un que invariable (6a), calificado tradicionalmente de que galicado, es decir, "calcado del francés", por pensarse que era debido a la influencia de esta lengua, como muestra el paralelismo de $(6 b)$.

(6) a. Es en México que se celebró el congreso.

b. C'est au Mexique que le congrès a eu lieu.

Trataremos de delimitar más adelante la aparición de este que invariable dentro de los cambios estructurales que han experimentado las construcciones hendidas en español. Antes de centrarnos en estos cambios, nos referiremos a la estructura informativa de las hendidas y a sus usos discursivos.

Por el hecho de contener una variable que se ha de especificar, la subordinada relativa de las hendidas tiene un carácter presupuesto, es decir, aporta una información que no se ve alterada por la negación o la interrogación de toda la construcción. En los ejemplos de (7), así, se preserva la inferencia de que 'alguien presentó a la conferenciante' y el foco de la negación y la interrogación recae sobre el constituyente referencial Guadalupe.

(7) a. No es Guadalupe la que presentó a la conferenciante.

b. ¿Es Guadalupe la que presentó a la conferenciante?

El carácter presupuesto de la relativa favorece que esta contenga información conocida y que el foco recaiga sobre el constituyente referencial. Es lo que sucede en los ejemplos anteriores, en los que el foco de la negación y la interrogación recaen en dicho constituyente, y también en la oración enunciativa y afirmativa de (1a), que reproducimos de nuevo en (8), indicando el foco mediante versalitas:

(8) Fue GUADALUPE quien presentó ayer al conferenciante.

En este tipo de oraciones, el foco es estrecho y contrastivo: es estrecho porque recae sobre un argumento o un adjunto de predicado (el argumento en función de sujeto en el ejemplo que estamos analizando), y contrastivo porque implica una lectura exhaustiva ${ }^{5}$, y por eso, la oración de (8) podría usarse como réplica a una aseveración previa:

—Pedro presentó ayer a la conferenciante, ¿verdad?

-No, fue GUADALUPE quien presentó ayer a la conferenciante. 
Las hendidas, sin embargo, no siempre presentan esta estructura informativa, como ya indicara Prince (1978) en un estudio sobre las hendidas del inglés que ha tenido una importante repercusión en los análisis posteriores. Los estudios basados en corpus, de hecho, muestran que las hendidas no siempre se utilizan como estrategia para expresar focos estrechos y contrastivos, y que también es posible, e incluso frecuente, que el foco sea amplio y presentativo, esto es, que recaiga en la relativa, o en esta y en el constituyente referencial, y que la relativa aporte información nueva a pesar de ser presupuesta 6 .

Sedano (1990: 21-22) caracteriza este tipo de construcciones de ecuativas, en el sentido que establecen una equivalencia entre las dos entidades vinculadas por la cópula, y Moreno Cabrera (1999: 4298-4299) considera que son construcciones con un uso discursivo meramente especificativo, puesto que no introducen la resolución de una alternativa, ni énfasis ni rectificación. Los casos más evidentes de este tipo de construcciones son aquellos en los que la hendida se usa con una función de cohesión discursiva (Núñez Alvarado 2012, Borreguero 2019, De Cesare 2017: 544-545, Dufter 2008: 1765, Gutiérrez Ordóñez 2015: 22, Goria 2013: 166-167, Helfrich 2003: 445-446, Raga 2018 154-156). En este uso, el constituyente referencial es o contiene una anáfora. Dicha anáfora mantiene la implicación de exhaustividad característica de las hendidas, pero al mismo tiempo se comporta como tópico, pues retoma una expresión referencial del discurso previo para darle continuidad discursiva. Es lo que encontramos en ejemplos como los de (10), en los que el antecedente y el constituyente referencial anafórico aparecen en cursiva, y la relativa aporta información nueva sobre el tópico.

(10) a. Belcourt habla francés, español, italiano, alemán. Es su dominio del italiano lo que le permite infiltrarse en la organización de la mafia que controla el tráfico de estupefacientes en Tánger [...]. (Sombra: 361)

b. [...] ella ha pedido una cena fría. Después, mientras esperaba la aprobación de Maestro, ha llamado a un servicio de taxis: Dijo que iba a la calle Reconquista. Es ahí donde vive, ¿no es cierto? (Vuelo: 234)

c. Los grandes empresarios del país se enriquecieron mucho en el ciclo largo de bonanza económica. Es por ello que esta vez no está tan claro que este golpe de Estado tenga su raíz en su posición en contra del modelo económico boliviano. (La Jornada, 17/11/2009: 28)

También tienen foco amplio y presentativo ejemplos como los de (11), en los que la hendida asume una función caracterizadora y la relativa aporta información nueva para especificar de manera neutra un constituyente referencial que se introduce en el discurso o que, al menos, no puede considerarse como tema discursivo.

(11) a. Fue César, un César al que ella recordaba más joven, quien la cogió después en brazos para alejarla de la ceremonia. (Tabla: 169) 
b. El aire estaba quieto en los cuartos, que se mantenían a oscuras porque es la luz la que trae el calor -decían los caseros-, la luz del día y las moscas por la noche. (Vuelo: 115)

c. Fue en el camino que va de la casa de un matrimonio a la del otro donde mataron a Ardines cuando salía, al alba, con su coche hacia el puerto para ir a pescar. (El País, 24/2/2019: 24)

De acuerdo con lo señalado, lo que caracteriza las hendidas es la escisión sintáctica de un constituyente del resto de la oración porque resulta prominente desde el punto de vista discursivo, sea por su carácter de foco o por su relevancia en el desarrollo del discurso. Este punto de vista, que no vincula las hendidas únicamente con estrategias de marcación de focos contrastivos, resulta especialmente productivo en el análisis diacrónico de estas construcciones y es el que adoptaremos en este trabajo ${ }^{7}$. Este punto de vista, además, nos permite tratar de manera unitaria las construcciones con cópula inicial y las construcciones con constituyente referencial inicial, puesto que unas y otras pueden presentar estructuras informativas semejantes.

\section{LAS CONSTRUCCIONES TÍPICAMENTE COPULATIVAS}

Si se acepta que las hendidas pueden presentar diferentes focos, no resultará problemático aceptar también que estas construcciones se documentan ya en latín (Dufter 2008: 1767-1768, Goria 2013: 161-167, Löfstedt 1966) y que del latín pasan a las lenguas románicas. Las hendidas del latín y de las lenguas románicas medievales, sin embargo, presentan importantes diferencias sintácticas y funcionales respecto a las hendidas actuales, como trataremos de mostrar a continuación.

En el castellano medieval, como en latín, las hendidas introducen sobre todo focos amplios y presentativos, y suelen asumir una función cohesiva (12a) o caracterizadora (12b).

(12) a.E plogo a los sabidores de la natura d'esta razón de dezir a estos peñedos venas del río Nilo, porque ellos son los qui primeramientre dan descubierta $e$ ciertas señales del primero miedo d'aquellos roídos del Nilo que viene nuevo con el primero comienço de la venida d'ellos. (GEI: 1.231)

b. E son dos las Mauritañas. E el rey Juba, padre del rey Tolomeo, fue el que primero regnó en amas las Mauritañas, segund cuenta Plinio. (GEI: 1.552)

Son menos habituales las hendidas con foco estrecho y contrastivo, y que asumen una función singularizante, de identificación de un elemento dentro de un conjunto explícito o implícito (13a), o correctiva o de rectificación (13b).

(13) a. Et todas las cosas que son criadas son mundo, mas él es criatura de Dios et Él lo crió quando Él tovo por bien et qual tovo por bien, et durará quanto Él 
tobiere por bien. Et Dios solo es el que sabe quándo se ha de acabar et qué será después que se acabare. (Lucanor: 319)

b.ACARIO. — ¿Que aquésta es tu hija? Tú mientes por mitad de la cara. ¿No está claro que dizes grandíssima falsedad y mentira?

Gitana. - Tú eres el que dizes la mentira, que aquésta es mi hija. (Rueda, Comedias: 252)

Como ocurre con cualquier otra copulativa, en estas construcciones el constituyente referencial es un sintagma nominal que funciona como sujeto y que, generalmente, ocupa la posición preverbal típica del sujeto. De hecho, las construcciones encabezadas por el constituyente referencial son las generales en textos medievales y modernos. Como puede observarse en el cuadro 1, las construcciones con el constituyente referencial antepuesto no bajan del $96 \%$ en textos medievales y son claramente mayoritarias en los textos de la edad moderna.

Cuadro 1. Construcciones con CRef o Cóp inicial en textos medievales y modernos

\begin{tabular}{|l|l|l|}
\hline Siglo & CRef inicial & Cóp inicial \\
\hline XIII & $96,4 \%$ & $3,6 \%$ \\
& $(53 / 55)$ & $(2 / 55)$ \\
\hline XIV & $100 \%$ & $0 \%$ \\
& $(78 / 78)$ & $(0 / 78)$ \\
\hline XV & $91,3 \%$ & $8,7 \%$ \\
& $(42 / 46)$ & $(3 / 46)$ \\
\hline XVI & $87,3 \%$ & $12,7 \%$ \\
& $(62 / 71)$ & $(9 / 71)$ \\
\hline XVII & $88,4 \%$ & $11,6 \%$ \\
& $(99 / 112)$ & $(13 / 112)$ \\
\hline XVIII & $85,6 \%$ & $14,4 \%$ \\
& $(89 / 104)$ & $(15 / 104)$ \\
\hline
\end{tabular}

La posposición del constituyente referencial, por otra parte, depende normalmente de los mismos factores que exigen, o que favorecen, la posposición de cualquier otro sujeto. La posposición, así, se justifica por el carácter no finito del verbo ser (14a), por el hecho de que el constituyente referencial es el foco de la negación (14b) o de la interrogación (14c), o por el hecho de que se trata de una oración subordinada (14d). 
(14) a. Acordaron los vecinos no ser el ratón el que este daño hacía, porque no fuera menos de haber caído alguna vez. (LT: 124)

b. "Non es este el que esleyo el Criador". (Fazienda: 201)

c. ¿Y es ésse el que llamáis Fabricio? (Rueda, Comedias: 208)

d. QUINCIA. —Sí, por mi vida; y aun que dezía que havías sido tú el que havías huydo. (Silva, Celestina: 160)

Si el constituyente referencial funciona como un sujeto, el relativo también tiene un carácter nominal. Por eso, inicialmente la relativa solo se puede construir con un pronombre relativo (i. e., quien o el relativo compuesto "artículo $+q u e$ "), aunque este no tiene que funcionar necesariamente como sujeto y puede aparecer seleccionado por una preposición. En los ejemplos analizados hasta ahora, el relativo es un pronombre no regido por ninguna preposición, que funciona como sujeto -(12), (13) y (14a y d) - o como complemento directo (14b y c). En los ejemplos siguientes, en cambio, asume funciones diferentes y aparece regido por una preposición: la función de complemento indirecto (15a), de adjunto de compañía en (15b) y de adjunto de causa en (15c).

(15) a. E cuand él es en la parte del cielo ó las estrellas del signo del León se ayuntan a las estrellas del signo del Cancro allí ó las estrellas Sirio, e ésta es a la que dizen Canícula [...]. (GEI: 1.225)

b. El quarto Dario regno en perssia \& fue ell onzeno Rey daquel regno despues del Rey çiro. \& este fue con el. Que el grand alexandre lidio. (Alfonso X, General Estoria. Cuarta parte, c 1280, CORDE)

c. Et si ouieren montes en los terminos deuen husar en eyllos assi como si fuessen una uezindat ambas las uillas. \& esto es por lo que no an partido los terminos. (Anónimo, Fuero Navarra. BNM ms. 248, 1300-1330, CORDE)

Inicialmente, por lo tanto, no se establece una concordancia funcional entre el constituyente referencial y el relativo, y aunque el relativo sea siempre un pronombre, puede aparecer regido por una preposición. Como ocurre en el español actual, la falta de concordancia funcional se puede evitar recurriendo al demostrativo de lejanía y, por lo tanto, a construcciones que se separan de las hendidas. Este demostrativo ocupa la posición que correspondería al antecedente del relativo y permite que los dos constituyentes enlazados por la cópula sean sintagmas nominales, como puede comprobarse en (16). En estos ejemplos, el relativo precedido de preposición funciona como complemento de régimen (16a), adjunto de compañía (16b) o adjunto causal (16c).

(16) a. e aun éste fue aquel de quien Moisén, que dio la ley de los judíos, fabló en su estoria e lo escrivió. (GEI: 1.56)

b. Cuando esto entendió doña Zulaime plogol e díxoles: —Dueñas, éste es aquel con quien me vós dezides mal. (GEI: 1.418) 
c. e esta niña es aquella por quem envió mio señor Abraham que la levasse por muger pora su fijo Isaac. (GEI: 1.290)

Menos frecuente es el uso del artículo en la posición que correspondería al antecedente, como muestran los ejemplos siguientes:

(17) a. 'Aquésta es la en que jamás non ovo peccado nin desfallesçimiento e ovo fructo de salvación a las ánimas'. (San Vicente Ferrer, Sermones, 1411-1412, CORDE)

b. ¡Ay, hijo de mis ojos, y qué disfraz es el con que has querido entrar en esta tu propria casa! (Alonso Fernández de Avellaneda, Don Quijote de la Mancha, 1614, España, CORDE)

c. Éstas son comidas de bendición, y las por que sospiramos en Salamanca [...]. (Juan Arce de Otárola, Coloquios de Palatino y Pinciano, c 1550, España, CORDE)

d. La distincion es la con que se distingue una palabra entre todas las demas por medio de rayas, ó de comas, ó de letras grandes. (Juan Francisco de Masdeu, Arte poética fácil, 1801, España, CORDE)

e. Con objeto de indagar si efectivamente se deriva de las leyes naturales de la sociedad un orden dado, veamos, primero, qué es lo a que se llama orden. (Eugenio María de Hostos, Tratado de sociología, a 1903, Puerto Rico, CORDE)

En los ejemplos anteriores de (17), el artículo mantiene la posición que corresponde a su valor etimológico de demostrativo de lejanía (i.e., ILLUM 'aquel' > el, ILLAM 'aquella' > la, etc.). Como apunta Girón Alconchel (2009: 1552), a pesar de tratarse de una construcción poco habitual, su uso es medieval (17a) y clásico (17b y c), pero también puede rastrearse en textos contemporáneos (17d y e). La construcción es regular, ya que equipara categorialmente los dos constituyentes enlazados por la cópula, pero, como señala Bello (1988 [1847]: 803-804), a pesar de ser "regular no es la que prefiere ordinariamente la lengua" y, por eso, se documenta poco y resulta agramatical o muy forzada en el español actual.

Resumiendo lo apuntado hasta ahora, se puede concluir que las construcciones hendidas presentan inicialmente las propiedades características de las oraciones copulativas prototípicas. Por ello: (i) el constituyente referencial es necesariamente un sintagma nominal en función de sujeto; (ii) este constituyente, además, ocupa generalmente la posición preverbal característica de esta función, y (iii) la subordinada relativa solo puede estar encabezada por un pronombre relativo, que puede asumir la función de sujeto u otra función precedida o no de preposición.

\section{LAS CONSTRUCCIONES CON CONCORDANCIA FUNCIONAL}

Sin ser habituales, las construcciones con un sintagma nominal sujeto y un relativo regido por una preposición se han continuado documentando hasta la actualidad, como muestran los ejemplos siguientes: 
(18) a. Éste es a quien yo le he dado / orden que a doña Lorenza, / en géneros, en encargos / y en dinero, facilite / de mi cuenta todo cuanto / le pida. (Sainetes: 230)

b. esto es en lo que se ocupan algunos escritores que pertenecen á un país, en que muy poco hay hecho, y en que mucho hay que hacer. (El Patriota, 1831, documento comentativo, Uruguay, CORDIAM)

c. La verdad de algo es, pues, ser en sí lo que ya era en su principio absoluto. Y esto es a lo que tradicionalmente se ha llamado esencia. (Xavier Zubiri, Naturaleza, Historia, Dios, 1932-1944, España, CORDE)

Se trata, como se ha indicado, de construcciones poco frecuentes en el español contemporáneo, que se suelen percibir como anómalas y que, por ello, no se recomiendan normativamente (RAEASALE 2009: 3025). El uso de este tipo de construcciones discordantes retrocede a partir del siglo XVI, momento en el que empiezan a documentarse construcciones en las que el constituyente referencial adopta una categoría correspondiente a la función del relativo. En estas nuevas construcciones, se producen concretamente dos cambios. Por una parte, el relativo deja de ser necesariamente un pronombre y puede ser también un adverbio (i. e., donde, cuando, como), y por otra parte, el constituyente referencial deja de ser necesariamente un sintagma nominal y adopta una categoría funcionalmente paralela a la del relativo. El constituyente referencial continúa siendo un sintagma nominal si el relativo es un pronombre no regido por preposición en función de sujeto (19 a y b) o de complemento directo (19c).

a. y a esta causa enbió un navio pequeño en nuestra busca, y con ciertos soldados, y por capitán d(e) ellos a un Cristóval de Olí, persona de valía y muy esforçado; y éste es el que fue maestre de canpo quando lo de Cortés. (Bernal: 39)

b. -Éstos, pues — dijo el cura-, fueron los que nos robaron. (Quijote I: 431)

c. -Bien puede eso ser así, y yo la tengo por buena usanza; pero eso debió de ser en los tiempos pasados, que ahora sólo se debe de acostumbrar a dar un pedazo de pan y queso, que esto fue lo que me dio mi señora Dulcinea, por las bardas de un corral, cuando della me despedí; y aun, por más señas, era el queso ovejuno. (Quijote I: 450)

Pero si el relativo está regido por una preposición o es un adverbio, el constituyente referencial tiende a adoptar la forma de un sintagma preposicional o de un adverbio funcionalmente equiparable al relativo o al sintagma con el relativo. En (20) se recogen ejemplos de sintagmas preposicionales: 
(20) a. Destos polvillos y de estas yerbecillas es de quien y acerca de quien ha de hacer su officio. (San Juan Bautista de la Concepción, De los oficios más comunes, c 1607, España, CORDE)

b. La luz del rostro de los prelados que tiene todas estas circunstancias es la luz que pide Dios tenga el prelado y con ésta es con quien hace sus obras y tareas conforme Dios manda [...]. (San Juan Bautista de la Concepción, Martirio que algunos prelados ocasionan a sus súbditos, c 1610, España, CORDE)

c. Sin embargo porque conmigo es con quien más continua mente se cerena y a quien regaladamente llama, y muchas occaciones le falto, themeroso de no errar. Y igualmente temo gravemente faltar a la charidad a esse ssanto Tribunal como ... piadosso. (DLNE, 1748: 229.558)

d. - Justamente, y por eso es por lo que hace falta la dispensa. (Francisco Navarro Villoslada, Doña Urraca de Castilla, 1849, España, CORDE)

e. Verdad es que en Toledo fue donde el francés hizo venir a su muger a parir a çinco meses [...]. (Sebastián de Horozco, Libro de los proverbios glosados, 15701579, España, CORDE)

f. [...] y en estas dos carreras es en donde es más perjudicial a la salud el fiambre salado, porque hay muchas pascanas de agua salitrosa y pesada, y la mucha bebida, sea de lo que fuese, es nociva, y la menos mala es la del aguardiente, tomado con moderación. (LCC: 16)

Y a continuación ejemplos en los que el constituyente referencial es un adverbio: de manera (21a), de lugar (21b) y tiempo (21c).

(21) a. y después de puestos en la Florida dixo que hera mijor viaje y más sercana navegaçión para ir a La Havana que no la derrota por donde avíamos venido. Y ansí fue como lo dixo; porque según yo entendí, avía venido con un Juan Ponçe de León a descobrir la Florida, avría ya catorze o quinze años, y allí, en aquella misma tierra, le desbarataron y mataron al Joan Ponse. (Bernal: 17)

b. Aquí es donde dize el coronista Gomara que fue Cortés la tierra adentro con quatroçientos soldados; no le informaron bien, qu(e) el primero que fue, es el por mí aquí dicho, y no otro. (Bernal: 109)

c. Ahora es quando se alegra mas de ser un buen patrióta [...]. (Papel periódico de la Ciudad de Santafé de Bogotá, 1791, Colombia, CORDIAM)

El cambio se produce por un proceso analógico nivelador, que generaliza a todos los contextos la concordancia funcional que inicialmente solo se da en casos como los de (12) y (13) citados más arriba, en los que el relativo es un pronombre que funciona como sujeto de la subordinada relativa y el constituyente referencial un sintagma nominal que funciona como sujeto de la oración principal. Estas oraciones, de hecho, son las más frecuentes (Castillo Hernández 2016) y pudieron 
servir de base para un cambio analógico que resultaba posible porque en estas construcciones, el verbo ser se comporta como un "copulativo puro" (Martínez 1994: 104-105), que se limita a establecer una relación de igualdad y está desprovisto de rasgos aspectuales.

Sea como fuere, este cambio supone un proceso de gramaticalización creciente de las construcciones hendidas, que las aleja de las copulativas más prototípicas, ya que el constituyente referencial difícilmente puede analizarse como el sujeto de una copulativa prototípica cuando adopta la forma de un sintagma preposicional o de un adverbio ${ }^{8}$.

\section{LA CONSTRUCCIÓN CON EL QUE GALICADO}

El segundo gran cambio sintáctico que se produce en las construcciones hendidas tiene que ver con la aparición del llamado que galicado. Este cambio es independiente de la posición de la cópula y afecta tanto a las construcciones con cópula inicial como a las que tienen el constituyente referencial en primera posición. El cambio implica un paso más en el proceso de gramaticalización de las construcciones hendidas y, por lo tanto, un mayor distanciamiento de las oraciones copulativas más prototípicas y un grado mayor de identidad construccional. Se documenta sobre todo en textos americanos a partir del siglo XviII y es poco habitual en el español peninsular. Se caracteriza por el hecho de que presenta un subordinante que invariable en lugar del relativo. Este subordinante se usa generalmente en casos en los que el constituyente referencial es un adjunto de predicado; por ejemplo, un adjunto instrumental (22a), un adjunto de tiempo (22b) o un adjunto de manera (22c).

(22) a. Con el engaño, con la impostura, con la sofistería de todo jénero, es que han de formarse la buena razon y la conciencia del pueblo? (El Patriota, Uruguay, 1831, CORDIAM)

b. A este ginete se allegaron a la costa del monte y se apearon y abian estado los ContraBandistas adentro del monte en vna zanga muy honda y se Asomo Vno y le zarago vn tiro entonzes fue que bieron que alli estaban lo que bieron esto átropellaron sobre ellos recularon Ellos átras de Vn palo grueso y vn zanga muy alta que Tenían ellos á su abono que prezisamente abian desubir los Blandenges por aquella zanga Ariba y fueron quatro [...]. (47, 1797, Uruguay, CORDIAM)

c. No es sin habilidad y mucho tino, que un ministerio puede poner en juego la ribalidad de los rematadores, descubrir el secreto de sus combinaciones, atinar con el verdadero punto de estimación á que las circunstancias han elevado aquello que se intenta enajenar y contraponiendo la fuerza del raciocinio á esa desconfianza que [s] us enemigos han tratado de infundir hasta en las clases que tienen menos que pensar y temer de lo futuro [...]. (El Patriota, 1831, Uruguay, CORDIAM)

Si tenemos en cuenta la cronología y los contextos en los que aparecen estas construcciones, se puede considerar que derivan de las construcciones con concordancia funcional y que se explican por un proceso de simplificación estructural. Esta simplificación, además, se produce 
inicialmente en contextos que corresponden a los relativos menos prototípicos (i. e., los adverbiales) o a las combinaciones de preposición y relativo más complejas estructuralmente (por eso es por lo que, gracias a eso es gracias a lo que). Como apuntan Stefano, Bentivoglio y Sedano (2017), el uso del subordinante general que es muy generalizado cuando el constituyente referencial es causal, y en este contexto se documenta también con cierta frecuencia en textos del español peninsular:

(23) a. Carlos Giménez ha pretendido con la obra, según ha señalado él mismo, devolver el protagonismo del teatro a los actores, y es por eso que los decorados y los efectos sonoros son realizados y movidos por los propios actores. (El País, 02/08/1980, España, CREA)

b. Es por eso que la Táctica de nuestros días, vista en los planos superiores, difiere esencialmente de la de ayer [...]. (Vicente Rojo, Elementos del arte de la guerra, 1947, España, CORDE)

El uso del que galicado es más tardío y menos frecuente si se trata de un complemento de régimen, como en (24a), y es casi inexistente, al menos en textos escritos, si el constituyente referencial es un argumento expresado por un sintagma nominal (24b).

(24) a. "O sea que es de esto que tengo que hablar." (Alfredo Bryce Echenique, Magdalena peruana y otros cuentos, 1986, Perú, CREA)

b. [...] si no puedo venir a esta casa no vengo más, pero acordate que sos vos que me llamás para que venga [...]. (Shila Vilker, Lo que digo me dice: 31 )

\section{EL ORIGEN DEL QUE GALICADO}

El origen de las construcciones con que galicado se ha justificado a partir de una influencia externa del francés (Bello 1988 [1847]: § 812, Cuervo 1914-1955 [1876]: 250), y por eso, el calificativo de galicado. Esta posible influencia externa, unida a su aparición tardía y a su escaso uso en el español peninsular, ha justificado su condena normativa, que solo se ha visto modificada con la publicación de la Nueva gramática de la lengua española, que ya no proscribe su uso (RAEASALE 2009: 3031-3033).

Las construcciones con el que galicado se encuentran bien documentadas en muchos de los grandes escritores hispanoamericanos contemporáneos, de los cuales no puede dudarse que utilicen una prosa canónica (25).

(25) a. No nos une el amor sino el espanto; / Será por eso que la quiero tanto. (Jorge Luis Borges, Buenos Aires)

b. Me parece que fue en ese momento que los dos nos alcanzamos en lo más hondo. (Julio Cortázar, Reunión y otros relatos, 1983, Argentina, CREA) 
c. Fue por esa época que concibió la idea de establecer un servicio de correo aéreo. (Gabriel García Márquez, Cien años de soledad, 1967, Colombia, CREA)

d. Fue por esto que recibió la segunda advertencia seria de la Curia. (Mario Vargas Llosa, La tía Tula y el escribidor, 1996, Perú, CREA)

Por otra parte, no todas las premisas en las que se basa la condena tradicional son necesariamente correctas. En primer lugar, su uso en el español de América está muy arraigado en la lengua popular, por lo que no parece posible que pueda deberse exclusivamente a una influencia literaria externa (Stefano, Bentivoglio y Sedano 2017: 114). Además, si la influencia externa es posible, su origen se puede explicar también por factores internos como han apuntado diferentes autores (Stefano, Bentivoglio y Sedano 2017: 115-116, Dufter 2008, Gutiérrez Ordóñez 2015: 2425). Nótese, por una parte, que una explicación basada únicamente en la influencia externa no podría justificar por qué la distribución del que galicado no coincide plenamente con la de los subordinantes paralelos del francés (que) y del inglés (that), que es mucho más general.

Por otra parte, como hemos tratado de justificar, la aparición del que galicado está motivada por una gramaticalización creciente de las construcciones hendidas, que cada vez se alejan más de las copulativas ${ }^{9}$. Este cambio, además, se constata en distintas lenguas europeas con grados diferentes: más en inglés que en francés, más en el portugués del Brasil que en el portugués europeo, más en el español americano que en el peninsular, etc.

Algunos autores, además, han cuestionado la proscripción tradicional con el argumento de que el que galicado no tiene un origen reciente y que su uso no puede deberse a una influencia externa porque se remonta a la lengua medieval (Dufter 2010: 267) o al español clásico (Stefano, Bentivoglio y Sedano 2017: 115-116). En los textos analizados del corpus, sin embargo, no hemos encontrado ejemplos antiguos claros de este uso. Los autores que hacen referencia al uso antiguo del que galicado justifican esta afirmación a partir sobre todo de ejemplos con el adverbio así, como los siguientes:

(26) a. E assí fue que allí andando morieron todos los más d'ellos [...]. (Alfonso x, General Estoria I, CORDE, ap. Dufter 2010: 267)

b. Y fue así qua luego otro día salimos para la villa a pedir limosna [...]. (El Lazarillo de Tormes, ap. Stefano, Bentivoglio y Sedano 2017: 116)

Es cierto que ejemplos como los anteriores podrían ser analizados como construcciones con que galicado, pues es posible interpretar que las secuencias en cursiva equivalen a 'y así fue como'. Sin embargo, también es posible interpretar que, en estos ejemplos, ser se usa con el significado de un verbo de acontecimiento ('suceder, ocurrir') y que la secuencia equivale a 'y sucedió así: que...'. Esta interpretación, de hecho, parece la más adecuada para los ejemplos anteriores si se incluye un poco más de contexto, y en el segundo caso, si se adopta además la puntuación de la edición que hemos utilizado para este trabajo. 
(27) a. E en todo esso contecióles allí lo que les amenazara Dios, que morrién muchos d'ellos en aquellas andadas, como avedes oído en las razones dichas que los quisiera Dios matar todos por los trasgreimientos e tuertos en que se levantavan contra Moisén e contra Aarón cerca'l mont Sinaí, e assí fue que allí andando morieron todos los más d'ellos [...]. (GEI: 2.745)

b.Visto esto y las malas burlas que el ciego burlaba de mí, determiné de todo en todo dejalle, y como lo traía pensado y lo tenía en voluntad, con este postrer juego que me hizo, afirmélo más. Y fue ansí, que, luego otro día salimos por la villa a pedir limosna, y había llovido mucho la noche antes; y porque el día también llovía, y andaba rezando debajo de unos portales que en aquel pueblo había, donde no nos mojamos [...]. (Lazarillo: 110)

Estas construcciones con el adverbio así no parece que se puedan considerar hendidas estrictas, pero son construcciones próximas, que podrían calificarse de hendidas eventivas y que tal vez contribuyeron al desarrollo posterior de las hendidas con que galicado.

Tampoco es un caso de construcción con que galicado el ejemplo de (28a), que en la edición utilizada en el corpus corresponde a (28b). En este caso, es por esto que no equivale a 'es por esto por lo que' sino a 'esta es la razón por la que'.

(28) a. Y antes que más pase adelante, aunque vaya fuera de orden, quiero decir por qué llamaban aquel puerto que he dicho de Matanzas, y esto traigo aquí a la memoria, porque ciertas personas me lo han preguntado la causa de ponerle aquel nombre, y es por esto que diré. Antes que aquella isla de Cuba estuviese de paz dio al través por la costa del norte un navío que [...]. (Bernal, ap. CORDE, ap. Stefano, Bentivoglio y Sedano 2017: 116)

b. Antes que más pase adelante y aunque vaya fuera de nuestra istoria, quiero dezir por que causa llamavan aquel puerto Matanças; y esto traigo aquí a la memoria porque me lo an preguntado un coronista que habla su corónica cosas acaescidas en Castilla. Aquel nonbre se le puso por esto que diré: que antes que aquella isla de Cuba se conquistase, dio al travez un navío en aquella costa [...]. (Bernal: 27)

Parece razonable pensar que, si el constituyente referencial es inicialmente un sintagma nominal que funciona como sujeto (véase supra § 2.1), no puedan documentarse casos de que galicado hasta que no desaparezca esta restricción a partir del siglo xvI. Por otro lado, en textos medievales la oración de relativo se construye con un pronombre relativo y no admite adverbios relativos. Por tanto, la interpretación de así es que como construcción con que galicado exigiría asumir que este aparece directamente, sin pasar por la construcción así es como ${ }^{10}$. Parece más razonable pensar que el que galicado es más tardío, sin que de ello se tenga que deducir que su origen se deba a una influencia necesariamente externa. 


\section{EL ORDEN DE LOS CONSTITUYENTES EN LAS HENDIDAS MÁS GRAMATICALIZADAS}

Como se ha indicado más arriba, las construcciones hendidas inicialmente suelen adoptar el orden típico de las copulativas y, por eso, generalmente aparecen encabezadas por el constituyente referencial (vs. más arriba el cuadro 1). Sin embargo, la gramaticalización creciente de las hendidas incide también en el orden de los constituyentes. Así, en los textos contemporáneos las construcciones con cópula inicial, que representan el orden más definitorio de las hendidas, se hacen cada vez más frecuentes. Como muestra el cuadro 2, en el siglo XIX el uso de construcciones con cópula inicial alcanza casi un tercio del total de construcciones del corpus y en los textos del siglo XX y XXI se sitúa alrededor del $50 \%$.

Cuadro 2. Construcciones con CRef o Cóp inicial en textos de la edad contemporánea

\begin{tabular}{|l|l|l|}
\hline Siglo & CRef inicial & Cóp inicial \\
\hline XIX & $68,1 \%$ & $31,9 \%$ \\
& $(79 / 116)$ & $(37 / 116)$ \\
\hline XX & $50,7 \%$ & $49,3 \%$ \\
& $(76 / 150)$ & $74 / 150)$ \\
\hline XXI & $48,1 \%$ & $51,9 \%$ \\
& $(75 / 156)$ & $(81 / 156)$ \\
\hline
\end{tabular}

Este nuevo patrón afecta, de hecho, a las construcciones más gramaticalizadas, esto es, a las construcciones con concordancia funcional $(29 \mathrm{a}-\mathrm{c})$ y a las construcciones con el subordinante general que (29d-f).

(29) a. Es en las leyes especiales y las complejas reglamentaciones e instituciones controladas por la Asamblea del Poder Popular y el Partido Comunista donde queda de manifiesto la ausencia de democracia en Cuba y su sustitución por un engranaje autoritario. (El País, 24/02/2019: 14)

b. Es ahora y sólo ahora cuando podemos formular responsablemente nuestra respuesta a la técnica. (Ciencia: 154)

c. -El camino del artista, y te hablo a ti, mi joven Alcibíades, o mejor Patroclo, o tal vez Sergio... El camino es salvar obstáculo tras obstáculo hasta que pueda asomarse al interior de sí mismo... Ardua tarea, si no tiene a mano un Virgilio que lo guíe. ¿Captas la fina parábola, jovencito?... Es así como el artista conoce, por fin, la libre delicia del más dulce gozo. (Tabla: 166) 
d. Cordova Mayo 7 de 1867 / Querida mamá: / Mi anterior a V. fue fecha 30 de Abril próximo pasado, y ahora tengo que anunciarle que el / consabido cólera ha desaparecido completamente del Rosario y Buenos Ayres -es por / eso que saldremos mañana con dirección á esos puntos-y además pienso quedarme / unos cinco dias en el Rosario ántes de pasar a Buenos Ayres dónde debo perman(ec)er / algún tiempo largo. (Cólera y negocios, Argentina, 1867, CORDIAM)

e. Yo no dí sacudidas á Silva, Segun declara alguno de los testigos, ni pasé del humbral de la carcel; y sí puedo probarle que estando, fué entonces que sacó el cuchillo, que yo antes no habia podido encontrarle [...]. (Queja de Diego Antonio Silva por maltratos físicos y verbales que recibió de un juez, Venezuela, 1832, CORDIAM)

f. También conduce a la defensa de mi parte ser falso como lo es el quere conprar flechas / para irse a los cumanches, porque aunque es asi que trato el que se las bendiecen, no fue / con ese fin sino con el de tener armas [...]. (105, EUA, 1747, CORDIAM)

Este orden, sin embargo, resulta forzado en las construcciones en las que el constituyente nominal funciona como sujeto y no hay concordancia funcional11:

a. ?*Es Andrea a la que se lo he dicho.

b. ?*Es esto por lo que he venido.

De acuerdo con esto se puede concluir que el aumento significativo de las hendidas con cópula inicial es una consecuencia más del proceso de gramaticalización y de convencionalización que experimentan las hendidas en el español contemporáneo.

\section{CONCLUSIONES}

Las hendidas son un tipo especial de construcciones sintácticas que permiten escindir, separar, mediante el verbo ser, un argumento o un adjunto de predicado del resto de la predicación, que se expresa mediante una relativa libre o semilibre. El objetivo de la escisión es marcar la prominencia discursiva del constituyente escindido, que tiene un carácter referencial y especifica la variable asociada al relativo.

Las construcciones hendidas se pueden usar con diferentes funciones discursivas y pueden presentar diferentes tipos de focos. Las hendidas más prototípicas se usan con una función correctiva o singularizante. En este caso, presentan un foco estrecho y la relativa contiene información conocida. Las hendidas, sin embargo, pueden asumir también una función de cohesión textual o identificadora, y en este caso, el foco es amplio y la relativa aporta información nueva a pesar de ser presupuesta. 
Inicialmente, las construcciones hendidas presentan las características generales de las oraciones copulativas. Por eso, el constituyente referencial o hendido es necesariamente un sintagma nominal que funciona como sujeto y ocupa la posición antepuesta al verbo propia del sujeto. El relativo, por su parte, es necesariamente un pronombre que, según la función que realice, puede aparecer solo o regido por una preposición.

A partir del siglo XVI, sin embargo, se producen cambios que alejan progresivamente las hendidas de las construcciones copulativas prototípicas. Ya desde el siglo XVI empiezan a documentarse construcciones en las que se establece una concordancia funcional entre el constituyente referencial y el relativo. En estas construcciones, el relativo deja de ser necesariamente un pronombre y puede ser también un adverbio (donde, cuando, como), y paralelamente, el constituyente referencial deja de ser necesariamente un sintagma nominal y adopta una categoría acorde con la función del relativo. A partir del siglo XVIII, se introduce un nuevo cambio, que se documenta sobre todo en el español americano, aunque no es totalmente desconocido en el peninsular. Este cambio consiste en el uso del subordinante general que en lugar del relativo, sobre todo en aquellos casos en los que el relativo funcionaría como adjunto de predicado y sería un adverbio o un pronombre regido por preposición. Tradicionalmente se ha considerado que este uso se debe a una influencia externa del francés y, por eso, el calificativo de "que" galicado. Sin embargo, el uso de este subordinante se puede explicar por causas internas, y se inscribe en un proceso de gramaticalización creciente de las construcciones hendidas, que presenta grados diferentes dentro de las lenguas románicas o entre variedades geográficas de una misma lengua. Otro síntoma de esta gramaticalización creciente es la consolidación de las hendidas con cópula inicial, que en el siglo XIX llega casi al tercio de las construcciones del corpus analizado, y en el siglo XX y XXI se sitúa alrededor del 50 \%. Todos estos cambios contribuyen, en resumen, a que las hendidas adquieran un grado cada vez mayor de identidad construccional.

\section{Corpus}

Abajo: M. Azuela, Los de abajo, edición de V. Díaz Arciniega, México: Fondo de Cultura Económica, Universidad Autónoma Metropolitana, Azcapotzalco, El Colegio Nacional, 2015 [1916].

Alcalde: P. Calderón de la Barca, El alcalde de Zalamea, edición de Á. Valbuena-Briones, Madrid: Cátedra, 1978 [1640].

Bandidos: M. Payno, Los bandidos de Río Frío, vol. 1, edición de M. Sol, México: Consejo Nacional para la Cultura y las Artes, 2000 [1810-1830].

Bernal: B. Díaz del Castillo, Historia verdadera de la conquista de la Nueva España. (Manuscrito Guatemala), edición de J. A. Barbón Rodríguez, México: El Colegio de México-Universidad Nacional Autónoma de México-Servicio Alemán de Intercambio Académico-Agencia Española de Cooperación Internacional, 2005 [c. 1568-1575].

Beso: M. Puig, El beso de la mujer araña, Barcelona: Seix Barral, 1976.

Busca: P. Baroja, La busca, Madrid: Caro Raggio, 1997 [1904].

Cárcel: D. de San Pedro, Cárcel de amor, en Cárcel de amor. Arnalte y Lucenda. Sermón, edición de J. F. Casanova, Madrid: Cátedra, 1995 [1482-1492].

Celestina: F. de Rojas, La Celestina, edición de D. S. Severin, Madrid: Cátedra, 1993 [c. 1499-1502]. 
Chica: E. Sevilla, De chica quería ser puta, México: Axial, 2009.

Ciencia: P. Laín Entralgo, Ciencia, técnica y medicina, Madrid: Alianza Editorial, 1986.

CN/Sí: L. Fernández de Moratín, La comedia nueva. El sí de las niñas, edición de J. Dowling y R. Andioc, Madrid: Castalia, 1975 [1792, 1805].

Corbacho: A. Martínez de Toledo, Arcipreste de Talavera o Corbacho, edición de J. González Muela, Madrid: Castalia, 1970 [1438].

CORDE: Real Academia Española, Corpus Diacrónico del Español http://www.rae.es.

CORDIAM: Academia Mexicana de la Lengua, Corpus Diacrónico y Diatópico del Español de América $<$ www.cordiam.org>.

CREA: Real Academia Española, Corpus de Referencia del Español Actual http://www.rae.es.

Cristiano y judío: Anónimo, Coloquio entre un cristiano y un judío, edición crítica y estudio preliminar de A. García Moreno, Londres: University of London, 2003 [1370].

Criticón: B. Gracián, El criticón, edición de M. Romera Navarro, 2 tomos, Filadelfia: Universidad de Pensilvania, 1938 [1651-1657].

Crónica: Cl. D’Ambruoso, Edición crítica y estudio de la Crónica Troyana promovida por Alfonso XI, Tesi doctoral, Universidade de Santiago de Compostela, 2012 [1350].

DEU: V. Bertolotti, M. Coll y A. Clara Polakof, Documentos para la historia del español en el Uruguay, vol. 2: Cartas personales y documentos oficiales y privados del siglo XIX, Montevideo: Universidad de la República, 2012 [XIX].

Diálogo: J. de Valdés, Diálogo de la lengua, edición de C. Barbolani, Madrid: Cátedra, 1990 [1535-1536].

DLNE: C. Company, Documentos lingüísticos de la Nueva España. Altiplano central, México: Universidad Nacional Autónoma de México, 1994 [XVI-XIX].

DOCAZ: Documentos jurídicos del Estado de Aguascalientes, México, 2008-2011.

DoCCM: Documentos jurídicos de la ciudad de México, Expedientes juicios civiles 1082/84, 1823/88.

El País: Diario El País, España, 24/02/2019.

El Patriota: Diario El Patriota, CORDIAM, 1822-1831.

Eloísa: E. Jardiel Poncela, Eloísa está debajo de un almendro, Madrid: Austral, 2011 [1940].

Encina: J. del Encina, Teatro completo, Madrid: Real Academia Española, 1893 [1496-1519].

Entremeses: M. de Cervantes, Ocho comedias y ocho entremeses nuevos, nunca representados, en M. de Cervantes Saavedra, Obras completas, edición de A. Rey Hazas, Madrid: Alianza Editorial, 2006 [1615].

Exequias: J. Pablo Forner, Exequias de la lengua castellana, edición de J. Jurado, Madrid: Consejo Superior de Investigaciones Científicas, 2000 [1795].

Fazienda: Almerich, La fazienda de Ultra Mar, edición de M. Lazar, Salamanca: Universidad de Salamanca, 1965 [c. 1200].

Fernando III: Crónica de Fernando III según el ms. Esc. X-I-4, fols. 321r-359v, en internet: http://www.hispanicseminary.org/t\&c/ac/index-es.htm [1340-1360].

Fuenteovejuna: F. Lope de Vega, Fuenteovejuna, edición de D. McGrady, Barcelona: Crítica, 1993 [1612].

GEI: Alfonso X, General estoria. Primera parte, edición de P. Sánchez Prieto-Borja, Madrid: Biblioteca Castro, 2 vols., 2001 [c. 1275]. 
Janis Joplin: É. Mendoza, El amante de Janis Joplin, México: Tusquets, 2001.

La Jornada: Diario La Jornada, México, 17/11/2009.

LBA: Arcipreste de Hita, Libro de buen amor, edición de A. Blecua, Madrid: Cátedra, 1992 [1330-1343].

LCC: A. Carrió de la Vandera “Concolorcorvo", El lazarillo de ciegos caminantes, edición de E. Carilla, Barcelona: Labor, 1973 [1773].

Líquido: Daniel Veronese, El líquido táctil, en Antología del teatro latinoamericano (1950-2007), 1: Argentina, compilación de L. Proaño Gómez y G. Geirola, Buenos Aires: CELCIT, pp. 434-454, 2017 [1997].

Lozana: F. Delicado, La lozana andaluza, edición de B. M. Damiani, Madrid: Castalia, 1969 [1528].

LT: Anónimo, Lazarillo de Tormes, edición de F. Rico, Madrid: Cátedra, 1987 [1554].

Lucanor: Don Juan Manuel, El Conde Lucanor o Libro de los enxiemplos del conde Lucanor et de Patronio, edición de J. M. Blecua, Madrid: Castalia, 1984 [1335].

Luna, mugeres: Á. de Luna, Libro de las virtuosas e claras mugeres, edición de Julio Vélez Sainz, Madrid: Cátedra, 2009 [1446].

Milagros: G. de Berceo, Los Milagros de Nuestra Señora, edición de C. García Turza, Madrid: Espasa-Calpe, 1992 [1246-1252].

Moamín: Moamín, Libro de los animales que cazan, edición de J. M. Fradejas Rueda, Madrid: Casariego, 1987 [1250].

Oculta: H. Abad Faciolince, La Oculta, Bogotá: Penguin Random House, 2014.

Parayso: C. de Sigüenza y Góngora, Parayso occidental, edición facsímil de la primera edición, México: Universidad Nacional Autónoma de México y Condumex, 1995 [1684].

Quijote: M. de Cervantes, Don Quijote de la Mancha, vol. 1, edición de F. Sevilla Arroyo y Antonio Rey Hazas, Madrid: Alianza Editorial, 1998 [1605].

Raquel: V. García de la Huerta, Raquel, edición de R. Andioc, Madrid: Castalia, 1982 [1778].

Regenta: L. Alas “Clarín”, La Regenta, vol. 1, edición de G. Sobejano, Madrid: Castalia, 1981 [1884-1885].

Rueda, Comedias: L. de Rueda, Las cuatro comedias, edición de A. Hermenegildo, Madrid: Cátedra, 2001 [1567].

Sainetes: R. de la Cruz Cano y Olmedilla, Sainetes I, edición de J. Dowling, Madrid: Castalia, 1981 [17651773].

Siervo: J. Rodríguez del Padrón, Siervo libre de amor, edición de E. Dolz, en Anexos de la Revista Lemir, 2004 [1445].

Silva, Celestina: F. de Silva, Segunda Celestina, edición de C. Baranda, Madrid: Cátedra, 1988 [1534].

Sombra: A. Muñoz Molina, Como la sombra que se va, Barcelona: Seix Barral-Planeta, 2014.

Tabla: A. Pérez-Reverte, La tabla de Flandes, Madrid: Alfaguara, 1990.

THE: P. Sánchez Prieto-Borja, Textos para la historia del español. II. Archivo municipal de Guadalajara, Alcalá de Henares: Universidad de Alcalá de Henares, 1995 [XIII-XVI].

Triunfo: J. Rodríguez del Padrón, Triunfo de las donas, en internet: http://www.cervantesvirtual.com/obravisor/triunfo-de-las-donas-y-cadira-de-onor--0/html/[c. 1443].

Valesco: A. Cabedo y S. Pons, Salvador (eds.): Corpus Val.Es.Co 2.0. http://www.valesco.es. 
Vida: D. de Torres Villarroel, Vida, ascendencia, nacimiento, crianza y aventuras, edición de G. Mercader, Madrid: Castalia, 1972 [1743-1758].

Vuelo: E. Martínez, El vuelo de la reina, Madrid: Alfaguara, 2002.

\section{Bibliografía}

Borreguero, M. (2019): "Cleft sentences in the history of Spanish: new evidence on the focusing vs. cohesive function debate", comunicación presentada en el workshop "When Data Challenges Theory": NonPrototypical, Unexpected and Paradoxical Evidence in the Field of Information Structure (Freiburg: Universität Freiburg, 15-16/2/2019).

Bello, A. (1988 [1847]): Gramática de la lengua castellana destinada al uso de los americanos. Ed. de R. Trujillo. Madrid: Arco Libros.

Bosque, I. (1998-1999): "Sobre la estructura sintáctica de una construcción focalizadora", Boletín de Filología 37, pp. 207-231.

CASTILlo HERNÁNDEZ, C. (2016): “The syntax pragmatics interface in the cleft sentences in Spanish”, póster presentado en el congreso internacional Syntax of the World's Languages VII (Ciudad de México: Universidad Nacional Autónoma de México, 17-20/8/2016).

CuERvo, R. J. (1914-1955 [1954]): Apuntaciones críticas sobre el lenguaje bogotano con frecuente referencia al de los países de Hispano-América. Bogotá: Instituto Caro y Cuervo.

DE Cesare, A. M. (2014): "Cleft constructions in a contrastive perspective”, en Anna-Maria De Cesare (ed.): Frequency, Forms and Functions of Cleft Constructions in Romance and Germanic. Berlin/Boston: De Gruyter, pp. 8-48. https://doi.org/10.1515/9783110361872.9

De Cesare, A. M. (2017): “Cleft constructions”, en A. Dufter y E. Stark (eds.), Manual of Romance Morphosyntax and Syntax. Berlin/New York: Mouton de Gruyter, pp. 536-568. https://doi.org/10.1515/9783110377088-015

DECLERCK, R. (1992): “The inferential 'it is that' construction and its congeners”, Lingua 87, pp. 203-230. https://doi.org/10.1016/0024-3841(92)90008-7

Di Tullio, Á. (2006): “Clefting in spoken discourse”, en K. Brown (ed.): Encyclopedia of Language and Linguistics. Amsterdam: Elsevier, vol. 2, pp. 483-491. https://doi.org/10.1016/B0-08-0448542/00564-2

Di Tulbio, Á. (2010): "Preguntas hendidas y preguntas segmentadas”, Cuadernos de la ALFAL (Nueva serie) 1, pp. 70-82.

DIEZ DEL CoRRAL, E.; GUTIÉRREZ MATE, M. (2015): “Introducción [al monográfico sobre Oraciones hendidas en el mundo hispánico: problemas estructurales y variacionales]”, Revista Internacional de Lingüística Iberoamericana 26, pp. 7-13.

DufTER, A. (2008): "Evolución pragmática de las oraciones hendidas en español: el papel de los usos no focalizadores", en C. Company Company y J. G. Moreno de Alba (eds.): Actas del VII Congreso Internacional de Historia de la Lengua Española. Madrid: Arco Libros, vol. 2, pp. 1763-1780.

DUFTER, A. (2010): "El que galicado: distribución y descripción gramatical”, en C. Sinner y A. Zamorano Aguilar (eds.): La excepción en la gramática española. Perspectivas de análisis. Madrid/Frankfurt am Main: Iberoamericana/Vervuert, pp. 253-278. https://doi.org/10.31819/9783865278722-012 
FERNÁNDEZ LEBORANS, M. JEsús (1999): “La predicación: las oraciones copulativas”, en I. Bosque y V. Demonte (dirs.): Gramática descriptiva de la lengua española. Madrid: Espasa, vol. 2, pp. 2357-2460.

Girón ALCONCHEL, J. L. (2009): “Las oraciones de relativo II. Evolución del relativo compuesto el que, la que, lo que”, en C. Company (dir.): Sintaxis histórica de la lengua española. Segunda parte: La frase nominal, México: Universidad Nacional Autónoma de México/Fondo de Cultura Económica, pp. 1477-1590.

GORIA, E. (2013): “Towards a taxonomy of Latin cleft sentences”, Journal of Latin Linguistics 12(2), pp. 147172. https://doi.org/10.1515/ioll-2013-0009

Guitart, J. M. (2013): “Del uso de las oraciones hendidas en el español actual”, Revista Internacional d'Humanitats 27: pp. 89-104.

GuTIÉRREZ ORDóÑEZ, S. (1986): Variaciones sobre la atribución, León: Universidad de León.

GuTIÉRREZ ORDóÑEZ, S. (2015): "La familia de las ecuacionales", Revista Internacional de Lingüística Iberoamericana 26, pp. 15-37.

Hartmann, K.; Veenstra, T. (2013): Cleft Structures. Amsterdam/Philadelphia: John Benjamins. https://doi.org/10.1075/la.208

HELFRICH, U. (2003): “Hendidas y seudo-hendidas: un análisis empírico-diacrónico”, en F. Sánchez Miret (ed.): Actas del XXIII Congreso Internacional de Lingüística y Filología Románica. Tubinga: Max Niemeyer Verlag, vol. 2.1, pp. 439-451. https://doi.org/10.1515/9783110946260-040

LAmbrecht, K. (2001): “A Framework for the Analysis of Cleft Constructions”, Linguistics 39, pp. 463-516. https://doi.org/10.1515/ling.2001.021

LÖFSTEDT, B. (1966): “Die Konstruktion c'est lui qui l'a fait im Lateinischen”, Indogermanische Forschungen 71, pp. 253-277.

MARTínEZ, J. A. (1994): “Construcciones 'ecuacionales': un dilema en gramática normativa”, Cuestiones marginadas de gramática española. Madrid: Istmo, pp. 41-82.

Meltzetin, M. (1989): “Zur Typologie der romanischen Spaltsätze”, en U. Klenk, K. H. Körner y W. Thümmel (eds.): Variatio linguarum. Beiträge zu Sprachvergleich und Sprachentwicklung Festschrift zum 60. Geburstag von Gustav Ineichen. Stuttgartt: Steiner, pp. 191-203.

Moreno Cabrera, J. C. (1983): “Las perífrasis de relativo”, en E. Alarcos Llorach et al. (eds.): Serta Philologica F. Lázaro Carreter. Madrid: Cátedra, pp. 455-467.

MoReno CABRERA, J. C. (1999): "Las perífrasis informativas: las perífrasis de relativo y otras construcciones perifrásticas”, en I. Bosque y V. Demonte (dirs.): Gramática descriptiva de la lengua española. Madrid: Espasa, vol. 3, pp. 4245-4302.

NÚÑEZ AlVARADO, V. (2012): “Función informacional de las escisiones en español”, LETRAS 1:51, pp. 163174.

PRINCE, E. (1978): “A comparison of wh-cleft and it-cleft in discourse”, Language 54, pp. 883-906. https://doi.org/10.2307/413238

PuSCH, C. (2003): “Die es que/c'est que-Konstruktion und ihre kommunikativen Dimensionen”, en G. Held (ed.): Partikln und Höflichkeit. Frankfurt: Peter Lang, pp. 295-317.

PusCH, C. (2006): "Marqueurs discursifs et subordination syntaxique: La construction inférentielle en français et dans d'autres langues romanes", en M. Drescher y B. Frank-Job (eds.): Les marqueurs discursifs dans les langues romanes. Approches théoriques et méthodologiques. Frankfurt: Peter Lang, pp. 173-188. 
RAE-ASALE (2009) = Real Academia Española y Asociación de Academias de la Lengua Española (2009): Nueva gramática de la lengua española. Madrid: Espasa.

RAGA, F. (2018): “Oraciones hendidas: identificación y significado procedimental”, Verba 45, pp. 131-165. https://doi.org/10.15304/verba.45.3907

SEDAno, M. (1990): Hendidas y otras construcciones con "ser" en el habla de Caracas. Caracas: Universidad Central de Venezuela.

Stefano, L. De; Bentivoglio, P; Sedano, M. (2017): "El uso del que galicado en el español actual”, Boletín de lingüística 29(47-48), pp. 112-124.

Toribio, A. J. (1992): "Proper Government in Spanish Subject Relativization”, Probus 4: 291-304. https://doi.org/10.1515/prbs.1992.4.3.291

ZUBIZARRETA, M. L. (2009): "Las funciones informativas: tema y foco”, en I. Bosque y V. Demonte (dirs.): Gramática descriptiva de la lengua española. Madrid: Espasa, vol. 3, pp. 4215-4244.

\section{Notas}

* Agradezco a Valeria Belloro, Margarita Borreguero, Ángela Di Tullio, Andreas Dufter y José Ignacio Hualde todos los valiosos comentarios y sugerencias que hicieron a una primera versión de este trabajo. Una parte de esta investigación ha sido realizada dentro del proyecto de investigación "Variación y cambio lingüístico en catalán. Una aproximación diacrónica según la Lingüística de Corpus” (MICINUN, Ref. PGC2018-099399-B-100371).

${ }^{1}$ En la tradición lingüística hispánica, las construcciones que analizamos en este trabajo también han recibido los nombres de escindidas, fórmulas perifrásticas de relativo, perífrasis de relativo, oraciones ecuacionales o copulativas enfáticas.

${ }^{2}$ La forma prefijada pseudo- se utiliza en aquellos casos en los que el orden y la estructura es similar a la de una oración copulativa. El adjetivo inversa, por otra parte, se asocia a la única construcción en la que la cópula no precede al constituyente referencial. Estas distinciones terminológicas resultan claras en lenguas como el inglés o el francés, donde las hendidas propiamente dichas tienen unas características claramente diferenciadas de las copulativas y donde las hendidas y pseudohendidas tienen estructuras sintácticas diferentes (p. ej.: It is coffee that I want vs. What I want is coffee), pero no lo es tanto en lenguas como el español donde las diferencias no son tan claras. Por eso, en los estudios sobre las hendidas del español o de otras lenguas románicas también es habitual designar los tres tipos de hendidas haciendo referencia al orden de los constituyentes (De Cesare 2014: 37-38, Gutiérrez Ordóñez 2015: 16, Moreno Cabrera 1999: 4251, RAE-ASALE 2009: 3021).

3 Tampoco analizaremos las llamadas construcciones con ser focalizador del tipo Presentó a la conferenciante fue Guadalupe, usadas en el español coloquial de diversos países hispanoamericanos. La mayoría de los investigadores que se han ocupado de estas construcciones considera que derivan de las pseudohendidas (Guitart 2013, Sedano 1990, Toribio 1992), por un proceso de simplificación estructural asociado a una gramaticalización creciente: Quien presentó $a$ la conferenciante fue Guadalupe > Presentó a la conferenciante fue Guadalupe. Hay, sin embargo, quien defiende que pueden tener un origen independiente (Bosque 1998-1999), que se explica por la posibilidad, documentada en lenguas diferentes, de utilizar la cópula como marca de foco.

4 Véase De Cesare (2017) para un análisis detallado de las diferencias existentes en las construcciones hendidas de las lenguas romances, tanto en las variedades europeas como americanas.

5 Sobre el carácter implicativo de la interpretación de exhaustividad en las hendidas, véanse, entre otros, Hartmann y Veenstra (2013: 20-24), y Raga (2018: 153-155).

${ }^{6}$ En las hendidas la presuposición tiene un carácter sintáctico, pues está motivada por la variable que se asocia al relativo y que tiene que ser especificada. Este carácter sintáctico hace que la presuposición no dependa del constituyente que se focaliza, como sí ocurre en un ejemplo como GUADALUPE presentó ayer a la conferenciante, que tienen una estructura 
informativa semejante a la de (8). Es, por lo tanto, este carácter sintáctico de la presuposición el que permite que las hendidas admitan diferentes estructuras informativas.

7 Teniendo en cuenta los diferentes usos discursivos de las hendidas no es extraño que diferentes autores definan estas construcciones sin hacer referencia a nociones informativas y centrándose exclusivamente en su estructura y en la posibilidad de que su contenido proposicional pueda expresarse mediante una oración simple paralela (Dufter 2008, Gutiérrez Ordóñez 2015, Lambrecht 2001: 467, Moreno Cabrera 1999: 4247-4251, RAE-ASALE 2009: 3020-3025, Sedano 1990: 14-18).

8 Para una discusión sobre la posibilidad de que el constituyente referencial funcione como sujeto en estas construcciones, véase Gutiérrez Ordóñez (1986: 63-69).

9 Por otra parte, como bien señaló Dufter (2010: 256-257), la substitución del relativo por el subordinante general que no es un fenómeno exclusivo de las hendidas y también se da en las relativas analíticas, en las que el subordinante que se combina con un posesivo o un pronombre que asume la función que correspondería al relativo dentro de la subordinada: Son personas que puedes confiar en ellas; Hablé con la chica que su padre trabaja en el ayuntamiento. Tanto en las hendidas como en las relativas analíticas, que se comporta como un mero subordinante y la función correspondiente al relativo queda expresada por otro constituyente de la oración.

${ }^{10} \mathrm{Ni}$ siquiera en francés, donde el proceso de gramaticalización de las hendidas es mucho más rápido e intenso, se documentan casos del subordinante general que en los textos medievales y "hay que esperar hasta el xvı para localizar las primeras perífrasis conjuntivas en la lengua de Molière" (Dufter 2010: 267).

${ }^{11}$ Aunque indicamos que estos ejemplos son de dudosa gramaticalidad, una rápida búsqueda en Google revela que expresiones como "es esto a lo que llaman" son de hecho bastante comunes en español actual. 